\title{
Desafios dos estudantes trabalhadores da UFPel (2019- 2020)
}

\author{
Challenges of working students at UFPel (2019-2020)
}

Milena da Silva Langhanz

Graduanda em Nutrição

Universidade Federal de Pelotas - UFPEL.

Pelotas, Rio Grande do Sul - Brasil.

milena.langhanz@gmail.com

DLorena Almeida Gill

Doutora em História.

Universidade Federal de Pelotas - UFPEL.

Pelotas, Rio Grande do Sul - Brasil.

lorenaalmeidagill@gmail.com

Resumo: O artigo pretende analisar as formas de trabalho encontradas pelos estudantes da UFPel para complementar a renda, necessárias, muitas vezes, para a sua manutenção na Universidade. Para isso, foram utilizados os conceitos de informalidade e vulnerabilidade social, a partir de autores como Antunes (1999), Pochmann (2008), Noronha (2003) e Castel (1997). A metodologia empregada foi uma análise quali-quantitativa, por meio do lançamento, nas redes sociais, de um questionário on-line via google forms, com trinta e três questões abertas e fechadas. Para a análise do conteúdo utilizou-se o software Excel. Coletou-se 184 respostas, de alunos oriundos de vinte e duas unidades acadêmicas e trinta e cinco diferentes graduações. As respostas, especialmente as abertas, apresentaram as dificuldades com as quais os estudantes vivem, bem como a necessidade de a Universidade mudar, tendo em vista não só incluir, mas fazer com que essas pessoas permaneçam no espaço educacional.

Palavras-chave: Estudante-trabalhador. Permanência estudantil. Vulnerabilidade social.

Abstract: The article aims to analyze the forms of work found by UFPel students to complement the income, often necessary for their maintenance at the University. For this purpose, the concepts of informality and social vulnerability were used, from authors such as Antunes (1999), Pochmann (2008), Noronha (2003) and Castel (1997). The methodology used was a quali-quantitative analysis, through the launch, on social networks, of a questionnaire online via google forms, with thirtythree open and closed questions. For content analysis, the Excel software was used. A total of 184 answers were obtained, involving students from twenty-two academic units and thirty-five different degrees. The answers, especially the open ones, presented the difficulties experienced by students, as well as the need for the University to change, with a view not only to include, but to make these people remain in the educational space.

Keywords: Student-worker. Student residence. Social Vulnerability. 


\title{
1 Introdução
}

O trabalho é uma atividade humana, objetiva e subjetiva voltada para a produção das condições necessárias à reprodução da vida individual e coletiva. Segundo Marx (1985, p. 297), o trabalho apresenta-se como categoria ontológica, ou seja, que expressa uma dimensão constitutiva da própria condição humana.

\begin{abstract}
Antes de tudo, o trabalho é um processo entre o homem e a natureza, um processo em que o homem, por sua própria ação, media, regula e controla seu metabolismo com a natureza. [...] Ele põe em movimento as forças naturais pertencentes à sua corporalidade, braços, pernas, cabeça e mão, a fim de apropriar-se da matéria natural numa forma útil para sua própria vida. Ao atuar, por meio desse movimento, sobre a natureza externa a ele e ao modificá-la, ele modifica, ao mesmo tempo, sua própria natureza. Ele desenvolve as potências nela adormecidas e sujeita o jogo de suas forças a seu próprio domínio.
\end{abstract}

Em termos sociológicos, o trabalho é uma atividade relacional, a partir da qual se consolidam interações sociais, econômicas, culturais, de afeto. Para entender, no entanto, as origens da informalidade no Brasil, faz-se necessário compreender como se deu a formação do mercado de trabalho brasileiro.

Duas ações estatais tiveram um impacto determinante na formação do mercado de trabalho brasileiro. A primeira foi a abolição da escravatura e, a segunda, o processo de modernização econômica iniciada nos anos 1930. Ambas produziram condições para a informalidade. $\mathrm{Na}$ primeira ação, o Estado não criou as circunstâncias necessárias para atender e oferecer emprego à população recém-liberta, contribuindo para o aumento da desigualdade, da pobreza e, com isso, produziu condições para que houvesse um excedente estrutural de trabalhadores, o que se chama hoje de setor informal. Ou seja, foi o Estado o responsável por perpetuar a exclusão de uma grande parte da população brasileira. Na segunda ação do Estado, como consequência da urbanização dos anos de 1930, o crescimento da população das cidades permitiu a migração para os grandes centros, o que resultou, principalmente, em regiões menos favorecidas com alta concentração de pobreza (RAMALHO e ARROCHELAS, 2004). Em ambos os casos, a ação do Estado reforçou o status quo em prol do crescimento de concentração de riqueza de um lado e, do outro, da miséria. A história do mercado de trabalho brasileiro esteve sempre permeada pela exclusão.

A ação do Estado sobre o mercado de trabalho baseia-se na ideia de crescimento econômico como uma possível política de emprego. O Estado assumiu uma posição de corresponsabilidade no que se refere à manutenção das desigualdades e às suas consequências, já que conseguiu forjar as bases da organização do assalariamento no país, porém, não as universalizou, e uma parte significativa da população manteve-se fora do assalariamento, reproduzindo a pobreza. De outra forma, a ação junto aos mais vulneráveis socialmente (CASTEL, 
1997) não se organizou para combater as desigualdades, que em épocas de crise no sistema capitalista e liberal ao qual o Brasil está inserido, não dá conta de atender a essa maioria da população, como se está vendo na pandemia da COVID-19. Conforme Pochmann (2008, p. 195):

A informalidade do trabalho é parte do processo histórico de formação e de desenvolvimento de uma economia periférica que se industrializou tardiamente. Por isso, há diversos tipos de produção e reprodução da informalidade, sobretudo porque o país se mostrou incapaz de realizar as chamadas reformas clássicas do capitalismo contemporâneo (agrária, tributária e social). A prevalência de um padrão de capitalismo selvagem também contribui para que a valorização do trabalho ficasse em segundo plano.

A informalidade é pensada, portanto, como um conceito histórico e sociológico, baseado em uma definição jurídica, ou seja, são informais os empregados que não possuem carteira de trabalho assinada, vínculo empregatício e diretos a benefícios, como férias e $13^{\circ}$ salário, dentre outros (NORONHA, 2003).

Para Antunes (1999, p. 209):

O mundo do trabalho viveu, como resultado das transformações e metamorfoses em curso nas últimas décadas, particularmente nos países capitalistas avançados, com repercussões significativas nos países de Terceiro Mundo dotados de uma industrialização intermediária, um processo múltiplo: de um lado verificou-se uma desproletarização do trabalho industrial, fabril, nos países de capitalismo avançado. [...] Mas, paralelamente, efetivou-se uma significativa subproletarização do trabalho, decorrência das formas diversas de trabalho parcial, precário, terceirizado, subcontratado, vinculado a economia informal, ao setor de serviços etc.

O fato é que as práticas de informalidade não são novas, ainda que tenham se agudizado com o passar do tempo. Atualmente, tem-se fortalecido um discurso mais positivo sobre elas, a partir de uma definição de que o trabalho por conta própria pode ser interessante a quem o executa. Diz-se que a pessoa pode atuar quando quiser, ser chefe de si mesmo, fazendo o seu horário e seus rendimentos, por exemplo. Para isso, comumente tem-se utilizado a palavra empreendedor.

A pandemia de COVID-19, no entanto, tem mostrado que a realidade de um pequeno empreendedor pode não ser tão fácil como parece para os seus defensores. O que fazer quando todo o comércio fecha, a economia entra em colapso e quando não é possível ter interação com as pessoas? Muitos dos chamados empreendedores do Brasil no tempo presente não conseguem ter recursos financeiros para sobreviver, tendo de recorrer às políticas governamentais para ter uma renda mínima, as quais, muitas vezes, são difíceis de acessar.

O mundo do trabalho, não só no Brasil como globalmente, tem sido marcado por uma proletarização a cada dia maior, assinalada por uma superexploração e pela retirada de direitos, a qual tem atingido um maior contingente de trabalhadores, desde aqueles com pouca formação 
educacional até a categorias que já foram mais prestigiadas e que agora convivem com um cenário bastante instável.

A última reforma trabalhista, efetivada no governo Temer, no que diz respeito ao Brasil, provocou profundas mudanças na Consolidação das Leis do Trabalho (CLT), a partir da premissa de combater o desemprego e a crise econômica. O que fez, no entanto, foi reforçar as dificuldades que os trabalhadores já vinham passando ao instituir o trabalho intermitente; agudizar a terceirização; flexibilizar jornadas e salários, fazer prevalecer o negociado sobre o legislado, dentre outros.

Em relação às universidades, até a década de 1970, as instituições de ensino superior brasileiras eram compostas, em sua maioria, por jovens que pertenciam à elite do país. Concluir um curso universitário significava prestigio social e um rápido retorno financeiro. Após o ano de 2012, foram criadas novas universidades públicas e ofertas de bolsas em instituições particulares (PROUNI), a partir da aplicação de recursos do FIES (Programa de Financiamento Estudantil), além da preconização de uma política de cotas. O FIES, por exemplo, promoveu o pagamento do curso de graduação para estudantes mais carentes, com auxílio do financiamento estatal das mensalidades, o qual só foi possível com o Plano Nacional de Educação (PNE) e o Programa de Apoio a Planos de Reestruturação e Expansão das Universidades Federais (REUNI) (VARGAS e PAULA, 2013; PEREIRA, 2019).

Um estudo do Observatório Universitário da Universidade Candido Mendes (2003), citado por Ristoff e Pacheco (2004, p. 9), demostrou que aproximadamente 25\% dos potenciais alunos universitários são tão carentes que "não têm condições de entrar no ensino superior, mesmo se ele for gratuito". Tal fato se dá devido às situações adversas que estes alunos apresentam em seus domić́lios, como não possuir geladeira e fogão, já que o rendimento domiciliar mensal da família é inferior a dois salários mínimos (NUNES, MARTIGNONI e CARVALHO, 2003).

A partir desses resultados, observa-se que alunos carentes, ao ingressarem na universidade, dependerão de bolsas de estudo, de trabalho, de monitoria, de extensão, de pesquisa, de restaurantes universitários subsidiados, de moradia estudantil ou de outras medidas que permitam a sua permanência na instituição. Por isso, faz-se necessário intensificar políticas públicas de inclusão social dos estudantes trabalhadores no plano nacional de assistência estudantil para alunos de baixa renda. Dessa forma, as pesquisas demostram que o trabalho atrapalha os estudos, porém, a ausência do trabalho pode impedir o universitário de estudar (VARGAS e PAULA, 2013).

Segundo a Pesquisa Nacional por Amostra de Domicílio (PNAD) de 2006, entre os jovens de 18 e 19 anos no Brasil, 27\% só estudavam. Entre os demais, 50,6\% trabalhavam, sendo que 
$30,6 \%$ somente trabalhavam e $20 \%$ trabalhavam e estudavam. Vale ressaltar que os afazeres domésticos compreenderam 17,2\% dos estudantes.

No grupo de 20 a 24 anos de idade, o trabalho passa a ser mais importante do que os estudos. Nessa faixa etária, 64,4\% trabalhavam, sendo que 49,7\% tinham como atividade exclusiva o trabalho e $14,7 \%$ associavam o trabalho ao estudo. O percentual correspondente ao grupo que somente estudava era de apenas 10,8\%, e 20,3\% cuidavam de afazeres domésticos (IBGE, 2007).

A mais recente pesquisa da PNAD, realizada no primeiro trimestre de 2020, demostrou que $12,2 \%$ da população está desocupada, entretanto, houve um aumento de 10,5\% do desemprego em relação ao trimestre anterior. Na mesma perspectiva, o Programa Internacional de Avaliação de Estudantes (Pisa), de 2015, evidenciou que 43,7\% dos estudantes de 15 anos trabalham antes ou depois das aulas.

A UFPel conta com um número considerável de cotistas, dentre eles os relacionados à uma renda familiar menor de 1.5 salários mínimos. Para citar um exemplo, no primeiro semestre de 2019, 634 alunos ingressaram nessa categoria. Precisa-se considerar que 50\% dos alunos ingressantes atualmente são cotistas, a partir do Sistema de Seleção Unificada (SISU) e, no caso do Programa de Avaliação da Vida Escolar (PAVE), 90\% das vagas são destinadas a alunos provenientes de escolas públicas, dentre eles muitos vinculados às cotas econômicas. Para a manutenção dos estudos dentro da universidade, a Pró Reitoria de Assuntos Estudantis (PRAE) oferta atualmente seis tipos de benefícios, além de cursos de geração de renda, acompanhamento psicopedagógico, bolsa permanência, entre outros auxílios, sendo que 3154 alunos recebem auxílio alimentação; 255, moradia estudantil e 1225, moradia, ou seja, o pagamento para que haja o aluguel de um local. Já 2118 recebem auxílio transporte; 241 alunos auxílio deslocamento; 218 auxílio pedagógico e 123 apoio pré-escolar.

Para esta pesquisa, realizada pelo PET Diversidade e Tolerância, os objetivos foram conhecer quais as formas de trabalho encontradas para complementar a renda; perceber as motivações que os levaram a procurar trabalho e saber se essa renda era determinante para a manutenção dos estudos.

\section{Metodologia e análise}

A metodologia utilizada foi uma análise quali-quantitativa, por meio de um questionário on-line formulado via google forms com trinta e três questões abertas e fechadas que possibilitaram a construção de pequenas narrativas, permitindo conhecer um pouco mais sobre a realidade dos alunos, incluindo o sentimento de cada um deles sobre a realidade de ser, ao mesmo tempo, aluno 
e trabalhador. As respostas foram dadas de forma anônima e assim serão utilizadas no texto, a partir da numeração: sujeito1, 2 e assim por diante. O formulário foi enviado aos estudantes de graduação da UFPel via redes sociais, durante os meses de março a junho de 2020 e, para a análise do conteúdo, foi utilizado o software Excel.

A pesquisa recebeu 186 respostas e após os fatores de exclusão (não trabalhou e não trabalha no mercado formal e informal e não estar na graduação) restaram 184 respostas. Esses alunos estão distribuídos em 22 unidades acadêmicas e em 35 cursos. Do total, 58,7\% dos respondentes se reconhecem como mulheres, 39,7\% como homens e 1,6\% preferiram não dizer.

De acordo com a composição étnica racial, 67,5\% dos alunos se consideram brancos $(n=124), 20,1 \%$ negros $(n=37), 11,4 \%$ pardos $(n=21), 0,5 \%$ amarelos $(n=1)$ e $0,5 \%$ outros $(n=1)$. Este dado indica uma superioridade de pessoas brancas na Universidade, embora exista uma política de cotas consolidada, conforme já dito.

Observa-se que a média de idade foi de 26 anos sendo a mais frequente a de 23 anos; dessa forma, 46,2\% dos estudantes pertencem à faixa de 21 a 25 anos. Vale ressaltar que 11,4\% dos estudantes possuem mais de 36 anos e 38,0\% dos estudantes ingressaram por ampla concorrência.

A partir da questão “com quem você mora?”, foi observado que 51,1\% dos estudantes não moram com a família. Tendo em vista essa classificação, 37,3\% dos estudantes vivem sozinhos; $34,0 \%$ em pensionatos, repúblicas ou dividem apartamentos com amigos; 25,5\% com o namorado(a), marido/esposa, filhos e/outros familiares (exceto pais) e 3,2\% na Casa dos estudantes UFPEL.

Uma das formas de renda citadas pelos estudantes está nos auxílios da PRAE, que possui uma política pedagógica de permanência, criando condições para que o estudante se alimente, se desloque, tenha moradia, além de todo o suporte necessário nas áreas afetivas, pedagógica e psicossocial que facilitam a inserção na vida universitária e o bom rendimento acadêmico, evitando a retenção e a evasão. Para isso, a PRAE recebe recursos do Programa Nacional de Assistência Estudantil (PNAES).

A partir desse amparo institucional, o qual é instituído após a concorrência em edital público e análise socioeconômica, foi observado que 57,6\% dos estudantes que participaram da pesquisa são bolsistas da PRAE e, destes, 76,4\% recebem mais de dois auxílios. Vale salientar que outra forma de conseguir obter renda dentro da universidade é a partir das bolsas de estudos (pesquisa, ensino e extensão).

Realizada a análise dos dados, foi possível observar que do total de estudantes que responderam a pesquisa, 92,3\% não recebem nenhum tipo de bolsa de estudos na universidade, 
independentemente dos auxílios da PRAE e 40,8\% dos estudantes não recebem nem auxílio da PRAE nem bolsas de estudos.

O trabalho formal é caracterizado pelo emprego com carteira assinada ou estabilidade financeira, além de outros direitos, conforme já dito, e foi observado que 30,9\% dos estudantes que participaram da pesquisa trabalharam no mercado formal em 2019. As principais atividades realizadas foram de recepcionista e auxiliar de escritório, seguido por garçom e vendas, além de outras diversas. Os estágios de curso não se enquadram em nenhuma das categorias, pois o aluno não possui vínculo empregatício nesse caso, porém, foram citados como forma de trabalho por aproximadamente $11 \%$ dos estudantes.

Já no mercado informal, 76,1\% dos estudantes atuaram em 2019 e 71,7\% trabalham atualmente. As porcentagens de trabalho formal e informal não são complementares, pois aproximadamente $20 \%$ dos estudantes realizam atividades formais e informais ao mesmo tempo, além disso, foram citadas diversas atividades realizadas ao longo do ano e os estágios remunerados foram contabilizados para os cálculos, uma vez que foram considerados fonte de renda.

A atividade informal mais citada foi freelancer, cujo termo abarca uma série de atividades que podem ser bastante diferentes. As demais atividades foram categorizadas em grandes áreas, destacando-se a de vendas, principalmente relacionadas ao comércio de doces, seguidos de roupas, alimentos em geral e cosméticos. A segunda área mais citada foi a da educação, por meio da qual os alunos lecionam conteúdos e saberes do seu domínio, principalmente relacionados aos cursos da licenciatura. Atividades consideradas como reprodutivas, por exemplo, diarista, costura e higienização de roupas foram listadas na sequência.

Um dos grandes problemas revelados pelos alunos é a disposição das disciplinas ao longo do dia, nos cursos diurnos, nos chamados currículos integrais. Muitas vezes, as disciplinas são ofertadas de forma desigual ao longo do dia e da semana, assim o aluno pode ter aula pela manhã, pela tarde e também nos dois turnos, nesse caso, pode haver intervalos entre as aulas, porém não são suficientes para o estudante ir para casa, trabalhar ou realizar qualquer atividade, tendo esse tempo ocioso perdido dentro da universidade. Dessa forma, o aluno precisa realizar suas atividades nos horários disponíveis, por isso, prefere atividades que possam ser exercidas fora do horário comercial, pois necessitam conciliar as aulas ao trabalho.

Mesmo utilizando os horários livres para o trabalho, os estudantes citam que, muitas vezes, precisam estar disponíveis a qualquer momento do dia, principalmente aqueles que trabalham como freelancer. Por exemplo, um fotógrafo precisa atender seus clientes via redes sociais ou por 
chamadas telefônicas a qualquer momento do dia, muitas vezes no horário de aula, o que implica em deixar de participar da atividade universitária para não perder aquele cliente.

Uma outra atividade bastante citada foi a venda de doces, a qual é realizada principalmente nas dependências da Universidade, próximo aos restaurantes universitários, com a finalidade de também garantir uma renda extra, ao incentivar o consumo de uma sobremesa antes do início de uma jornada. Não se pode esquecer que Pelotas é conhecida como cidade do doce, portanto, é comum que as pessoas que aqui chegam logo queiram conhecer a tradição doceira.

Como observado anteriormente, somente uma atividade laboral, muitas vezes, não é suficiente para suprir as necessidades financeiras dos estudantes. Como exemplo, pode-se citar a realização de entrevistas de pesquisas. Essa atividade, geralmente, é realizada em alguns dias da semana e o aluno/trabalhador só recebe o pagamento pelos dias trabalhados. Para compensar, no intervalo entre uma pesquisa e outra, faz-se necessário realizar outra atividade como freelancer em eventos, por exemplo, para que a renda seja suficiente.

Da mesma forma, a associação do trabalho formal e informal acontece. As atividades home office permitem que o estudante trabalhe otimizando seu tempo livre e, até mesmo, aproveitando o tempo ocioso entre as aulas presenciais. Esse tipo de prática é relevante, porém, no período de coleta de dados, poucos estudantes que realizam essas atividades responderam à pesquisa. Entretanto, com a pandemia de COVID-19, essa forma de atuação aumentou consideravelmente, sendo que uma parcela da população migrou do trabalho presencial para o home office. Portanto, é possível que o número de estudantes trabalhando de casa deva ter aumentado, da mesma forma que o número de trabalhadores informais. Em relação às novas adaptações diante do cenário de distanciamento social provocado pela pandemia, julga-se necessário realizar novas pesquisas que abordem as especificidades desse período.

Cabe mencionar que esta pesquisa foi elaborada antes da pandemia de COVID-19, porém, a coleta de dados ocorreu durante o isolamento social. Com isso, as respostas obtidas continham informações de antes e durante a quarentena. Portanto, compreende-se que na questão que abordava dificuldades ao trabalhar um estudante relatou que foi demitido com a chegada da pandemia e uma diarista que trabalhava para vários clientes com horários fixos na semana mencionou que com a pandemia restou somente um cliente, diminuindo consideravelmente a frequência das faxinas.

A renda do trabalho é necessária para a sobrevivência de $83,7 \%$ dos estudantes que participaram da pesquisa. E, perguntados sobre o pagamento de dívidas, 48,9\% relataram que, às vezes, conseguem se manter e pagar suas contas; $36,4 \%$ que efetivamente conseguem pagar as 
contas e 14,7\% que não conseguem nem mesmo pagar os gastos básicos. Três participantes relataram que após a demissão do trabalho formal, começaram a trabalhar no mercado informal para manter a renda.

Sobre a evasão dos universitários, 63,0\% relataram que já desistiram ou pensaram em desistir de frequentar as aulas/universidade por falta de dinheiro para se manter; 53,3\% afirmaram que já faltaram à aula por falta de dinheiro. Tal fato pode ter se dado a partir de vários problemas. A locomoção, por exemplo, de um lugar a outro (a UFPel tem cerca de 30 prédios distribuídos pela cidade de Pelotas e Capão do Leão) é difícil e, algumas vezes, demora um pouco para que os alunos tenham acesso aos auxílios.

Para avaliar a manutenção dos estudos, foi feita a seguinte pergunta: "Se a universidade desse algum tipo de auxílio para manter os estudos você deixaria de trabalhar?”. A partir da questão, 46,2\% universitários relataram que deixariam de trabalhar e 37,5\% disseram que talvez deixariam de trabalhar se recebessem um auxílio. Em relação às bolsas, 38,6\% relataram que se tivessem uma bolsa de estudos deixariam de trabalhar, 40,8\% relataram que talvez deixassem de trabalhar e 20,6\% relataram que não deixariam de trabalhar.

Mais de $50 \%$ dos estudantes narraram que já procuraram ajuda da PRAE e outros 72,3\% afirmaram nunca terem feito algum curso profissionalizante de curta duração. O relato a seguir, de uma das respondentes, demonstra as dificuldades relacionadas aos cursos e auxílios:

[...] É claro que se houvesse uma bolsa capaz de suprir minhas necessidades básicas como moradia, alimentação, saúde e materiais de estudo eu poderia dar o tempo que passo trabalhando para melhorar meu desempenho acadêmico e aproveitar ao máximo o meu período de graduação. Acho que estar fazendo um curso já é suficientemente complexo e acrescentar uma jornada de trabalho complica mais um pouco, mas não é possível (sobre)viver com $\mathrm{R} \$ 400,00$ numa cidade com o padrão de vida de Pelotas [...] (SUJEITO $1)$.

Um outro estudante que participou do projeto de geração de renda ofertado pela PRAE relatou que:

[...] O projeto de geração de renda e permanência da PRAE abriu muitas possibilidades pro meu trabalho, participei de $80 \%$ das feiras de artesanatos organizadas pelo projeto, fiz novos contatos, o número de vendas aumentou, teve meses que só com as vendas das feiras consegui bancar as contas do mês[...] (SUJEITO 2).

A grande maioria dos participantes afirmou que trabalha por necessidade e apenas 7,6\% revelaram que trabalham porque gostam ou estão à procura de experiência profissional. Ainda, $6 \%$ deixou bastante explícito que atua para complementar a renda familiar.

Os universitários narraram muitas dificuldades, entre elas o reduzido tempo livre para realizar as atividades laborais conciliando com as aulas e a incerteza de conseguir renda suficiente para suprir as necessidades básicas, como apresentam os relatos a seguir: 
O que considero que tenha sido complexo é conciliar o trabalho com as atividades acadêmicas considerando que além do período em aula há uma grande quantidade de exercícios, leituras etc. que precisam ser realizadas em casa e quando se precisa acordar todos os dias às 05:00 se torna uma tarefa exaustiva (SUJEITO 3).

Ou ainda:

Sim. Muitas vezes ao fazer estágio recebia somente o necessário ou para comer ou para pagar aluguel, às vezes atrasava aluguel pra poder comprar algo mais para comer [...]. Quanto ao curso sempre fiz com muita dificuldade, pois geralmente não tinha muito tempo para estudar e nem para realizar algumas atividades diurnas. Em parte do meu curso quase nem dormia, pois tinha que me manter acordada durante a madrugada para fazer trabalhos e estudar para prova e no dia seguinte trabalhar o dia todo e ir a aula à noite. Ficava de virada noites e noites (SUJEITO 4).

Dessa forma, os estudantes narram que não possuem tempo livre, aumentando o cansaço físico e mental em consequência do trabalho e estudo executados ao mesmo tempo. Por trabalharem, inclusive, nos finais de semana, o desempenho no curso de graduação é prejudicado, já que os horários apertados entre uma atividade e outra não permitem que o estudante vá para casa, por exemplo, dedicar-se com maior tranquilidade às atividades acadêmicas.

Um relato de um universitário que vendia alimentos na universidade demostra essa situação:

\footnotetext{
Sim, eu insisti. Por algumas semanas mesmo com o braço machucado. Não conseguia mais tomar notas das aulas nem fazer exercícios, até que minhas notas começaram a cair. Por isso parei. Depois meus avós nos deram uma mão, a mãe do meu marido passou a mandar mais dinheiro e pudemos continuar [...] (SUJEITO 5).
}

O preconceito também foi citado como um fator agravante sobre as dificuldades de se exercer uma atividade. Os modos como se expressaram, indicaram que o estigma era direcionado à questão racial ou, ainda, devido ao tipo de trabalho exercido. Uma das entrevistadas, que se autodeclarou negra, assim disse: "Com certeza, principalmente o cansaço e o preconceito enfrentado por ser formada, continuar estudando e estar fazendo limpeza. Há indiferença na forma como as pessoas nos tratam".

Outra questão importante que aparece em alguns dos formulários foi o medo que atinge as mulheres que trabalham à noite, além da desvalorização dos serviços prestados, por não possuir garantias. Se a estudante for mãe solo, então, a dificuldade aumenta, pois precisa se desdobrar para cuidar dos filhos, estudar e trabalhar ao mesmo tempo. Existe, no entanto, uma bolsa para alunas que forem mães de crianças menores do que 5 anos, mas o processo para o recebimento, algumas vezes, é um pouco demorado. Se a estudante for uma mulher mais velha, também pode passar por dificuldades oriundas da discriminação. Segundo uma das narradoras: 
[...] Também existe o problema da discriminação. Se em uma entrevista de emprego você diz que estuda... Adeus oportunidade. Outra é quanto à idade, eu tenho 45, na minha juventude me foi dado duas escolhas: estudar ou trabalhar. E como sempre fui pobre e, na maior parte da minha vida, morei no interior, trabalhar foi o que me restou (SUJEITO $6)$.

O relato a seguir demostra as dificuldades de organização que os universitários possuem relacionados à concomitância de atividades do trabalho e estudo:

[...] conciliar produção de peças para a venda (porque temos que comer, pagar o aluguel) e estudos é complicado, tenho peças que demoram de 4 a 5 horas para serem produzidas, mas tenho que estudar, dormir, produzir trabalhos pra faculdade e essa disputa de prioridades acaba afetando muito nosso psicológico [...] (SUJEITO 7.)

A demora para receber os auxílios, a incompreensão de alguns professores e a falta de experiência para realização das atividades foram citadas, pelos respondentes, como pontos negativos e que prejudicam ainda mais os estudos.

Por fim, os estágios remunerados (que ocorrem na área de formação do estudante levando em conta a carga horária de estudos e disponibilidade de tempo e ainda se apresentam como uma fonte de renda) tornam-se um problema, pois a regulamentação existente não permite mais de 2 anos em um estágio, dessa forma, é preciso deixar aquela atividade que mantinha o sustento. E, muitas vezes, não é fácil conseguir um outro estágio rapidamente.

Entre as ações que a universidade poderia fazer para garantir a permanência do estudante na universidade e também seguir para uma pós-graduação, os estudantes relataram que é necessário organizar melhor a carga horária dos cursos, a fim de manter as disciplinas em um único turno. Outra solução seria ofertar mais cursos noturnos e a distância, pois atualmente estas possibilidades são pequenas.

\section{Considerações finais}

Ingressar em um curso universitário não é tarefa fácil, pois requer, muitas vezes, um estudo preparatório intenso. Para uma parcela grande de alunos pode ser ainda mais dificultoso, a considerar que não possuem condições adequadas para se organizarem visando o ingresso em uma universidade gratuita.

De todo o modo, se existem adversidades para o ingresso, os maiores obstáculos se dão com relação à permanência. Segundo dados do Instituto Nacional de Estudos e Pesquisas Educacionais (INEP), no Brasil, para o ano de 2010, apenas 33\% dos alunos concluíram a sua graduação no tempo regular. Caso fossem adicionados três anos a este tempo, a taxa subiria para $50 \%$. 
Fala-se, neste artigo, de alunos, em sua maioria, em vulnerabilidade social, ou seja, provenientes de famílias de baixa renda, de escolas públicas e que possuem pouco acesso a livros, cursos e equipamentos, os quais poderiam facilitar seus estudos, além de apresentarem fragilidade de apoios relacionais. Muitos deles advêm de regiões bem longínquas de Pelotas e, para que se estabeleçam, necessitam de um recurso financeiro inicial que, algumas vezes, a base familiar não possui.

Nesse sentido, a pesquisa revelou as dificuldades de se conciliar uma graduação a um ou mais trabalhos. Não só porque, muitas vezes, não sobra tempo para uma dedicação adequada, mas também tendo em vista que a estrutura da Universidade não costuma pensar em estudantes que, para se manterem, necessitam atuar, seja de maneira formal ou informal.

Nota-se que a pesquisa não conseguiu abarcar o período da pandemia da COVID-19, o que poderia revelar ainda mais a dificuldade desses alunos conseguirem uma manutenção adequada. Para isso, pensa-se em observar esta realidade a partir de um novo formulário.

De todo modo, ainda que a Universidade tenha sido elogiada quanto a suas políticas de cotas, que já existem faz alguns anos e também com relação aos auxílios concedidos, seria o tempo dessa instituição se reinventar centrando o seu olhar para a maioria da população, ou seja, àqueles que possuem rendas mais baixas e que, por isso, além do desejo de estudar, precisam trabalhar.

Algumas medidas poderiam amenizar essa situação, como o oferecimento de um maior número de cursos noturnos e atividades a distância; uma melhor adequação de horários para cursos chamados de integrais; uma aceleração na concessão de auxílios, além de uma maior fiscalização sobre quem efetivamente tem direito. O estudo é uma análise que se baseia em números, mas, sobretudo, em narrativas, que contam os percalços de se estudar e trabalhar em um país tão desigual.

\section{Referências}

ANTUNES, Ricardo. Os sentidos do trabalho: Ensaio sobre a afirmação e a negação do trabalho. São Paulo: Boitempo, 1999.

BRASIL. Documento final, 2010. Disponível em: <http://conae.mec.gov.br/images/stories/pdf/pdf/documetos/documento_final_sl.pdf>. Acesso em 10 de julho de 2020.

CASTEL, Robert. A dinâmica dos processos de marginalização: da vulnerabilidade à "desfiliação". CADERNO CRH, Salvador, n. 26/27, p. 19-40, jan./dez. 1997. Disponível <www.cadernocrh.ufba.br/include/getdoc.php?id=1012\&article>. Acesso em 20 de julho de 2018. 


\section{Dialogia}

LANGHANZ, Milena da Silva; GILL, Lorena Almeida. Desafios dos estudantes trabalhadores da UFPel

IBGE. 2007. Síntese de indicadores sociais: uma análise das condiç̃es de vida da população brasileira.

Disponível em: <https://biblioteca.ibge.gov.br/visualizacao/livros/liv36151.pdf>. Acesso em 21 de jul. de 2020.

INEP. <http://portal.inep.gov.br/artigo/-

/asset_publisher/B4AQV9zFY7Bv/content/melhorar-a-taxa-de-conclusao-do-ensino-superiore-uma-das-prioridades-do-governo-federal/21206>. Acesso em 17 de julho de 2020.

MARX, Karl. O Capital: crítica da economia política. São Paulo: Abril Cultural, 1985.

NORONHA, Eduardo. "Informal”, ilegal, injusto: Percepções do mercado de trabalho no Brasil. RBCS, Vol. 18 n'. 53 outubro/2003 disponível em:

<http://www.scielo.br/pdf/\%0D/rbcsoc/v18n53/18081.pdf >. Acesso em 3 de julho de 2020.

NUNES, Edson, MARTIGNONI, Enrico e CARVALHO, Márcia. Perfil dos egressos, quotas e restrições: uma observação da educação superior no momento de sua reforma. Documento de trabalho n. 32. Observatório Universitário. Jul/ 2004. Disponível em:

<http://www.observatoriouniversitario.org.br/principal.htm>. Acesso em 3 de julho de 2020.

PEREIRA, Lucinéa. O estudante de camadas populares na universidade pública: permanência garantida? Cadernos da Pedagogia, v. 12, n. 24, p. 16-29, jan/jun 2019.

PNAD-SÍNTESE INDICADORES DE 2006. IBGE.

$<$ https:/ $/$ biblioteca.ibge.gov.br/index.php/ biblioteca-catalogo? $v i e w=$ detalhes\&id $=236018>$. Acesso em 10 de setembro de 2020.

PACHECO, Eliezer, RISTOFF, Dilvo. Educação Superior: Democratizando o acesso. Instituto Nacional de Estudos e Pesquisas Educacionais Anísio Teixeira, 2004. 22 p. - (Série Documental. Textos para Discussão, ISSN 1414-0640; 12).

POCHMANN, Marcio. O emprego no desenvolvimento da nação. São Paulo: Boitempo, 2008.

PNAD-CONTINUA. IBGE. < https://www.ibge.gov.br/estatisticas/sociais/habitacao/9173pesquisa-nacional-por-amostra-de-domicilios-continua-trimestral.html?edicao $=27704 \& \mathrm{t}=$ quadrosintetico $>$. Acesso em 4 de julho de 2020.

RAMALHO, Jether; ARROCHELAS, Maria Helena et al. Desenvolvimento, subsistência e trabalho informal no Brasil. São Paulo: Cortez, 2004.

VARGAS, Hustana e PAULA, Maria. A inclusão do estudante-trabalhador e do trabalhadorestudante na educação superior: desafio público a ser enfrentado. Avaliação, Campinas; Sorocaba, SP, v. 18, n. 2, p.459-485, jul. 2013.

Recebido em: 15 set. 2020/ Aprovado em: 13 nov. 2020

Cite como

(ABNT NBR 6023:2018) 


\section{Dialogia}

LANGHANZ, Milena da Silva; GILL, Lorena Almeida. Desafios dos estudantes trabalhadores da UFPel

LANGHANZ, Milena da Silva; GILL, Lorena Almeida. Desafios dos estudantes trabalhadores da UFPel (2019- 2020).Dialogia, São Paulo, n. 36, p. 581-594, set./dez. 2020. Disponível em: https://doi.org/10.5585/dialogia.n36.18188.

\section{American Psychological Association (APA)}

Langhanz, M. S., \& Gill, L. A. (2020, set./dez.). Desafios dos estudantes trabalhadores da UFPel (2019- 2020). Dialogia, São Paulo, 36, p. 581-594: https://doi.org/10.5585/dialogia.n36.16791. 